\title{
Volcanic unrest at Hakone volcano after the 2015 phreatic eruption: reactivation of a ruptured hydrothermal system?
}

Kazutaka Mannen ${ }^{1 *} \mathbb{D}$, Yuki Abe', Yasushi Daita², Ryosuke Doke', Masatake Harada' ${ }^{1}$ George Kikugawa', Naoki Honma ${ }^{3}$, Yuji Miyashita' and Yohei Yukutake ${ }^{1}$

\begin{abstract}
Since the beginning of the twenty-first century, volcanic unrest has occurred every 2-5 years at Hakone volcano. After the 2015 eruption, unrest activity changed significantly in terms of seismicity and geochemistry. Like the pre- and co-eruptive unrest, each post-eruptive unrest episode was detected by deep inflation below the volcano ( $10 \mathrm{~km})$ and deep low frequency events, which can be interpreted as reflecting supply of magma or magmatic fluid from depth. The seismic activity during the post-eruptive unrest episodes also increased; however, seismic activity beneath the eruption center during the unrest episodes was significantly lower, especially in the shallow region $(\sim 2 \mathrm{~km})$, while sporadic seismic swarms were observed beneath the caldera rim, $\sim 3 \mathrm{~km}$ away from the center. This observation and a recent InSAR analysis imply that the hydrothermal system of the volcano could be composed of multiple sub-systems, each of which can host earthquake swarms and show independent volume changes. The 2015 eruption established routes for steam from the hydrothermal sub-system beneath the eruption center ( $\geq 150 \mathrm{~m}$ deep) to the surface through the cap-rock, allowing emission of super-heated steam $\left(\sim 160^{\circ} \mathrm{C}\right)$. This steam showed an increase in magmatic/hydrothermal gas ratios $\left(\mathrm{SO}_{2} / \mathrm{H}_{2} \mathrm{~S}\right.$ and $\left.\mathrm{HCl} / \mathrm{H}_{2} \mathrm{~S}\right)$ in the 2019 unrest episode; however, no magma supply was indicated by seismic and geodetic observations. $\mathrm{Net} \mathrm{SO}_{2}$ emission during the post-eruptive unrest episodes, which remained within the usual range of the post-eruptive period, is also inconsistent with shallow intrusion. We consider that the post-eruptive unrest episodes were also triggered by newly derived magma or magmatic fluid from depth; however, the breached cap-rock was unable to allow subsequent pressurization and intensive seismic activity within the hydrothermal sub-system beneath the eruption center. The heat released from the newly derived magma or fluid dried the vapor-dominated portion of the hydrothermal system and inhibited scrubbing of $\mathrm{SO}_{2}$ and $\mathrm{HCl}$ to allow a higher magmatic/hydrothermal gas ratio. The 2015 eruption could have also breached the sealing zone near the brittle-ductile transition and the subsequent self-sealing process seems not to have completed based on the observations during the post-eruptive unrest episodes.
\end{abstract}

Keywords: Hakone volcano, Phreatic eruption, Hydrothermal system, Sealing zone, Cap-rock, Volcanic unrest, Scrubbing of magmatic gas

\section{Introduction}

Phreatic eruptions have no direct involvement of magma and are instead driven by the thermal energy of

\footnotetext{
*Correspondence: mannen@onken.odawara.kanagawa.jp

1586 Iriuda, Odawara, Kanagawa 250-0031, Japan

Full list of author information is available at the end of the article
}

hydrothermal water. However, thermal energy itself is mainly provided by heat from magma, and recent geophysical observations have revealed that deep intrusion of magma or magmatic fluid precedes phreatic eruptions. The uncertain time lag between such an intrusion and the eruption makes forecasting phreatic eruptions extremely 
challenging (Stix and De Moor 2018), as demonstrated by a series of eruptions of Ontake volcano recently.

The 2007 phreatic eruption of Ontake volcano was preceded by a magma intrusion at a depth of approximately $3 \mathrm{~km}$ beneath the eruption center, approximately 2 months before the eruption (Nakamichi et al. 2009). In contrast, the 2014 phreatic eruption of the volcano, which killed more than 60 trekkers in the summit area, was only preceded by a volcano-tectonic earthquake swarm that started 17 days before the eruption and no magmatic intrusion seems to have preceded it (Takagi and Onizawa 2016). However, surprisingly, the ejecta of the 2014 eruption contained a trace amount of juvenile (magmatic material newly emplaced beneath the surface) fragments, and a series of geological investigations implied that the magmatic body intruded to $3 \mathrm{~km}$ deep beneath the volcano just before the 2007 eruption was released by the 2014 eruption (Miyagi et al. 2020). This sequence implies that an eruption can be triggered by an intrusion event years prior. We, thus, cannot estimate eruption probability based only upon intensity of volcanic unrest or source depth of deformation, especially when a series of eruptions and/or unrest episodes have occurred recently at the volcano. For such eruption types, evaluation of volcanic unrest based upon models of the interaction between the hydrothermal system and magma intrusions is critical to avoid underestimation of eruption probability.

Hakone volcano, located near the nation's capital Tokyo, is one of the largest tourist destinations in Japan and attracts more than three million tourists annually to the site of previous phreatic eruptions, named Owakudani (Owakidani) steaming area (Fig. 1). At this volcano, episodes of volcanic unrest have repeated every few years since the beginning of the twenty-first century, and eventually in 2015, a small phreatic eruption occurred at Owakudani steaming area (Mannen et al. 2018). Even after this eruption, volcanic unrest continued to take place, and evaluation of these events has yet to be done. Here, we summarize the recent episodes of volcanic unrest and discuss possible future phreatic activity.

\section{Background}

Hakone volcano and its activity in the twenty-first century

Here, we review Hakone volcano and its latest activity based on Mannen et al. (2018). Hakone is a caldera volcano located approximately $80 \mathrm{~km} \mathrm{SW}$ of Tokyo (Fig. 1a). Its eruption history started at least 400 ka with two caldera-forming stages. Andesitic effusive eruptions since $40 \mathrm{ka}$ have formed a complex of lava flows and domes named the Younger Central Cones (YCC) in the center of the caldera (Fig. 1b). At $3 \mathrm{ka}$, the latest magmatic eruption occurred near the northernmost part of YCC and formed a lava dome named Kanmurigatake, which erupted within an amphitheater that was created by a sector collapse just before the dome formation. The most active steaming area and the center of the latest phreatic eruptions named Owakudani is located at the eastern flank of Kanmurigatake.

Hakone is not very active in terms of magmatic eruptions; however, it is notable for its high seismicity, with at least 7 intense earthquake swarms observed in the twentieth century. Most of the swarms did not accompany clear intensification of steaming activity, while the volcanic unrest from 1933 to 1935 culminated with the formation of a new steam vent $1 \mathrm{~km}$ south of Owakudani, although the exact location of the vent is not known.

The continuous instrumental monitoring of Hakone volcano started after the volcanic unrest of 1959-1960; however, the first major seismic swarm to be detected by the network did not occur until 2001. The 2001 unrest consisted of an earthquake swarm, and deep and shallow inflation as observed by Global Navigation Satellite System (GNSS) and a tiltmeter network, and culminated with a blowout of a steam production well (SPW) in Owakudani (SPW52, $500 \mathrm{~m}$ deep; Fig. 1c). Since the 2001 unrest, major volcanic unrest episodes comprising earthquake swarms, deep inflation detected by a GNSS network, and deep low frequency events (DLF) were observed in 2006, 2008-2009 and 2013 (Harada et al. 2018; Yukutake et al. 2019). These volcanic unrest episodes were not accompanied by significant increases of steaming activity in the steaming areas of the volcano; however, in March 2015, a new volcanic unrest episode started with a deep inflation and increase of both volcanotectonic (VT) and DLF seismicity. This volcanic unrest was followed by a blowout of SPW (SPW39 in Fig. 1c) in early May, and eventually, on June 29, a small phreatic eruption started and lasted until the early morning of July 1. The 2015 volcanic unrest after the eruption seems to have continued until late August, which is evident from crustal inflation monitoring by GNSS (Harada et al. 2018).

\footnotetext{
(See figure on next page.)

Fig. 1 Index map of Hakone volcano. a Location of Hakone volcano. b Shaded relief map of Hakone volcano. C Sampling locations. Blue lines indicate the Owakuzawa River and its tributary. Red star, soil gas location; yellow circles, fumarole; green squares, steam production well (SPW). The two digits before the hyphen indicate year of emergence (e.g., fumarole 15-2 was formed in 2015). Since the eruption crater and fumaroles are formed in an area within $100 \mathrm{~m}$ from the SPW52, the area is called an eruption center area
} 


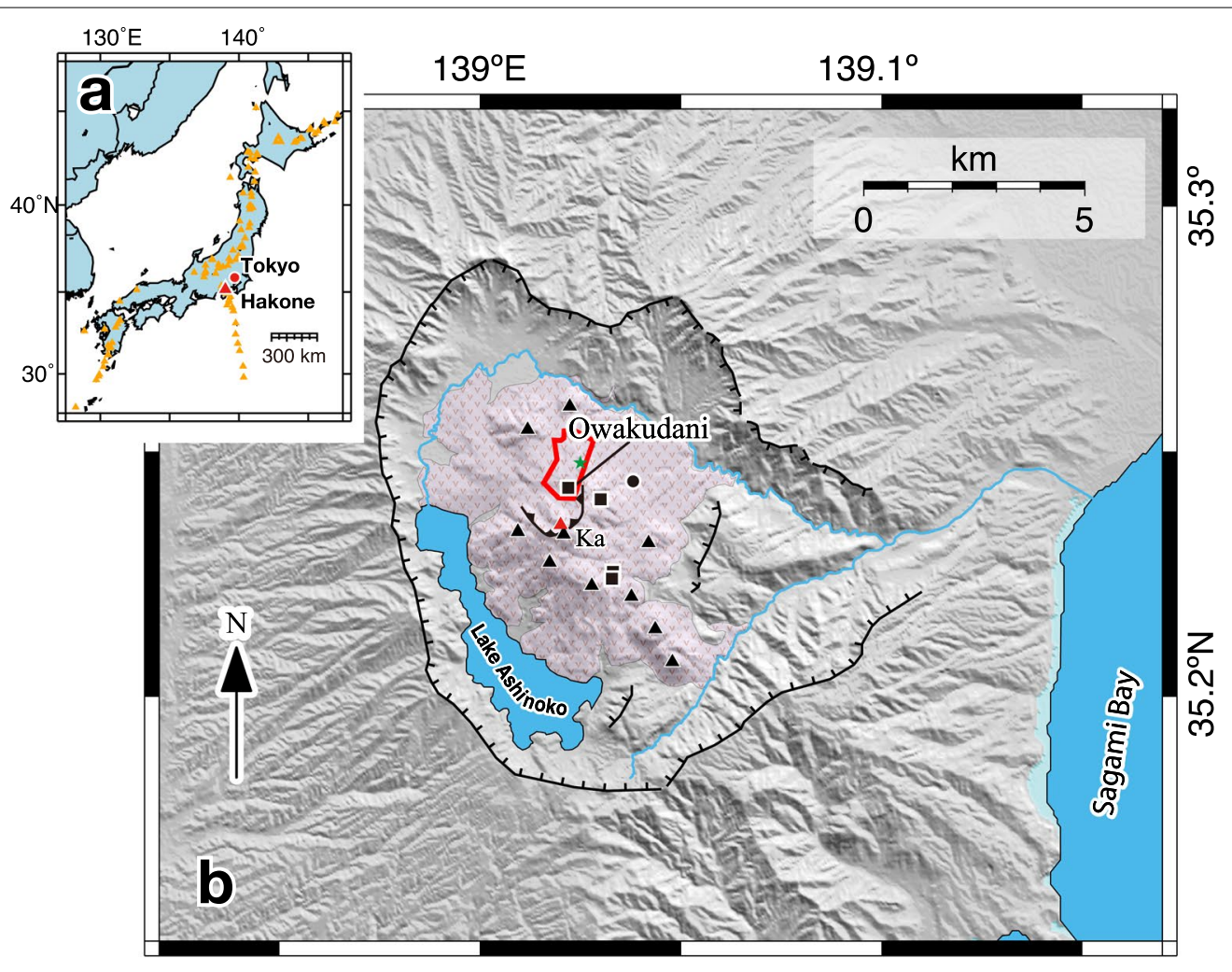

Legend
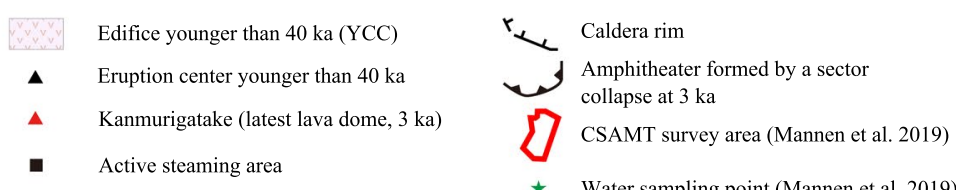

$\star \quad$ Water sampling point (Mannen et al. 2019)

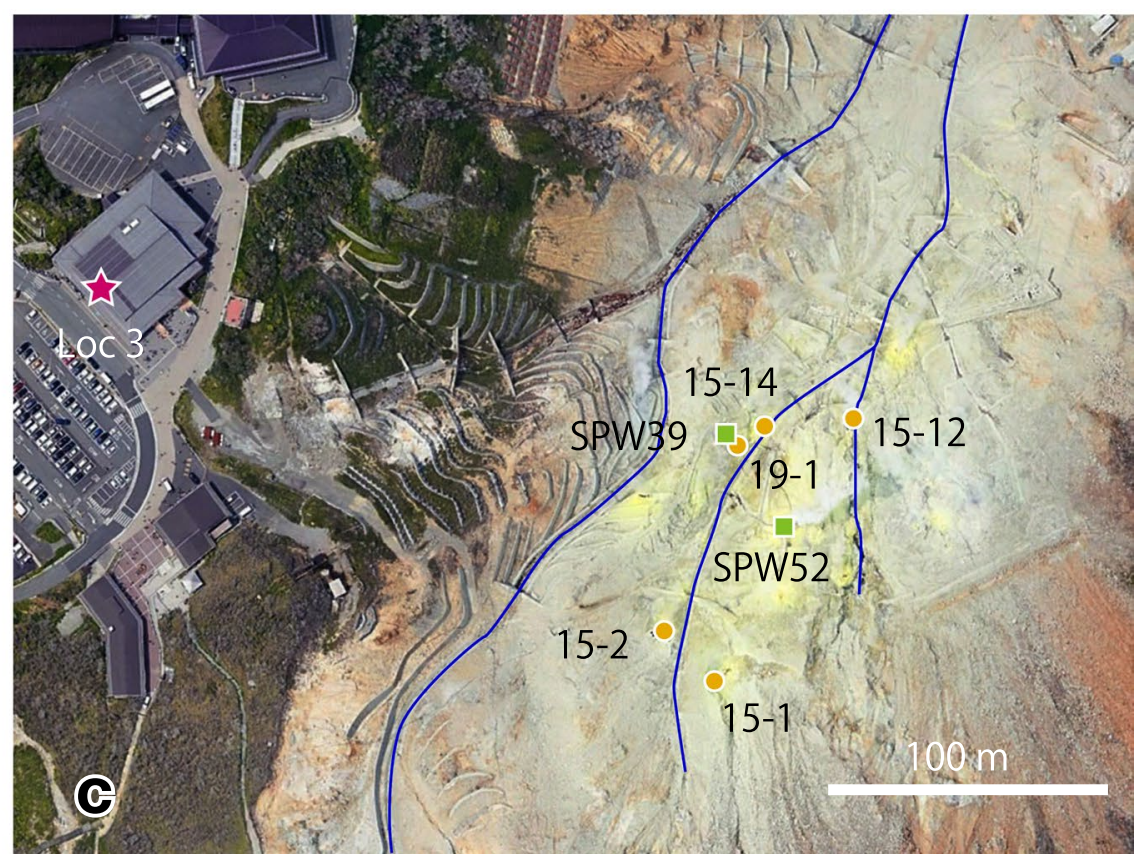




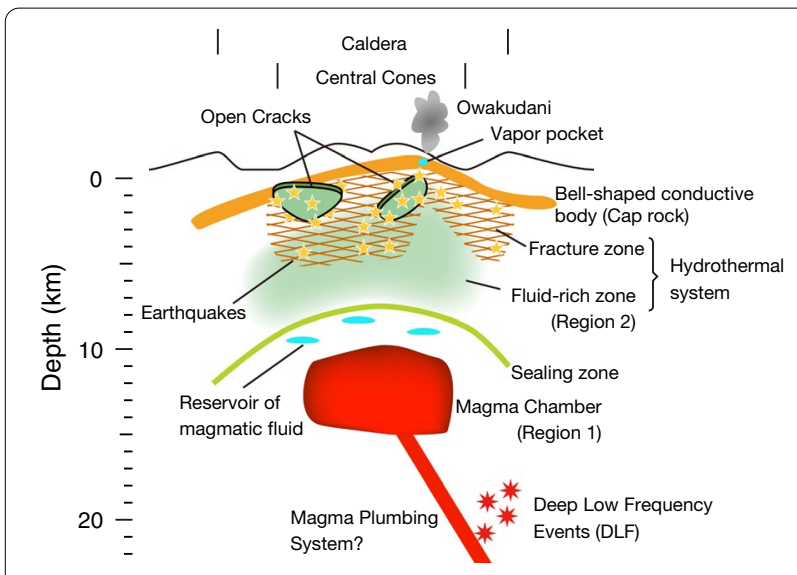

Fig. 2 A schematic model of subsurface structure of Hakone volcano. Diameter of the caldera is approximately $10 \mathrm{~km}$; however, structure beneath the volcano such as magma chamber and open crack are not to scale. This model is a modified version of previous models (Yukutake et al. 2015; Mannen et al. 2018) based on recent studies (Doke et al. 2018; Kobayashi et al. 2018; Yoshimura et al. 2018; Mannen et al. 2019; Ohba et al. 2019; Yukutake et al. 2019)

\section{Subsurface structure of Hakone volcano}

Various geophysical and geochemical investigations over the last decade have modeled the subsurface structure of Hakone volcano. They are summarized in Fig. 2 and as follows. At approximately $20 \mathrm{~km}$ beneath the northern caldera rim of the volcano, DLFs occur sporadically. Since many of the DLF swarm events were followed by inflation of the edifice and shallow VT earthquake swarms, DLFs are interpreted as a signal indicating migration of magmatic fluid (Yukutake et al. $2015,2019)$. A seismic tomography study revealed the velocity structure beneath Hakone volcano and showed that the volcano has an active magma-hydrothermal system (Yukutake et al. 2015). Yukutake et al. (2015) identified a high-Vp/Vs and low-Vs body and named it Region 1, which was considered to represent a magma chamber located at approximately $10 \mathrm{~km}$ depth. Above Region 1, a low-Vp/Vs and low-Vs body (Region 2) was identified and interpreted as a fluid-rich zone. The upper boundary of Region 2 is shallower than $5 \mathrm{~km}$, and interestingly, the boundary seems to reach near the surface just beneath Owakudani. Above Region 2 is a fracture zone, where most of the VT earthquakes occur. Some fraction of the VT earthquakes in the fracture zone of Hakone volcano can be attributed to reactivation of pre-existing fractures caused by fluid migration (Yukutake et al. 2010, 2011). Significant anisotropy in the shallow crust beneath Hakone volcano also indicates pre-existing fractures that are controlled by the regional stress field (Honda et al. 2014). The fracture zone and Region 2 overlap slightly and both are considered to form the hydrothermal system.

A magnetotelluric study in and around Hakone volcano revealed a bell-shaped conductive body beneath the volcano, the top of which reaches the surface near Owakudani (Yoshimura et al. 2018). Since the bellshaped conductive body nests a resistive body beneath it, they are considered to represent the hydrothermal system of the volcano. The bell-shaped body is interpreted as a smectite-rich zone, which was formed by the prolonged hydrothermal activity of the volcano. In Owakudani and the surrounding area (Fig. 1), a series of local high-resolution magnetotelluric surveys was conducted and revealed that the bell-shaped conductive body is exposed on the surface in the bottom of Owakudani valley (Mannen et al. 2019; Seki et al. 2020). A geological investigation of a borehole showed that the bell-shaped conductive body corresponds to altered volcanic sediment accompanying smectite as predicted by Yoshimura et al. (2018) (Mannen et al. 2019; Seki et al. 2020). Hypocenters of VT earthquakes at Hakone are located within the resistive body (i.e., hydrothermal system) (Yoshimura et al, 2018). Peculiarly, seismic signals other than VTs, such as volcanic tremor and low frequency events, are rare in this volcano. The only shallow non-VT seismic events detected by our network were an isolated shallow $M=0.3$ event that occurred near Owakudani during the 2006 unrest (Tanada et al. 2007) and tremors sourced from the boiling conduit during the 2015 eruption (Yukutake et al. 2017). Since shallow tremors and low frequency earthquakes are common in volcanoes that have active hydrothermal systems, the paucity of shallow seismic signals related to the migration of fluids even during volcanic unrest episodes could be a significant feature of Hakone volcano.

Geochemical monitoring has provided evidence for development of a sealing zone (Fig. 2) and injection of magmatic fluid into the hydrothermal system through the zone (Ohba et al. 2019). Very shallow geological and resistivity structures $(\leq 500 \mathrm{~m}$ deep) were summarized by Mannen et al. (2019); the very shallow inflation source of the 2015 eruption (Doke et al. 2018; Kobayashi et al. 2018), which was interpreted as a vapor pocket located $150 \mathrm{~m}$ deep beneath the eruption center (Fig. 2; surface elevation is approximately $1000 \mathrm{~m}$ above sea level), was determined by a high-resolution magnetotelluric survey (CSAMT) to be a high resistivity zone within the apex of the bell-shaped conductive body (Yoshimura et al. 2018). 


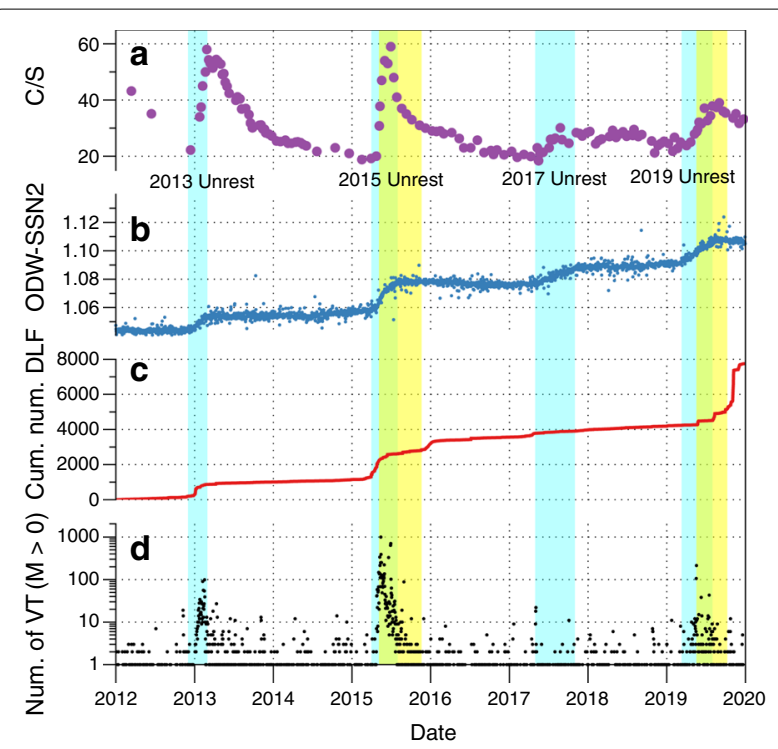

Fig. 3 Sequential change of a) $\mathrm{CO}_{2} / \mathrm{H}_{2} \mathrm{~S}(\mathrm{C} / \mathrm{S})$ molar ratio of fumarole gas emitted from a fumarole in Owakudani (Daita et al, 2019; Ohba et al, 2019), b) baseline length across Hakone volcano (Odawara Susono2 + 20,747 m), c) cumulative number of deep low frequency events, and d) daily number of volcano-tectonic earthquakes in Hakone volcano. Durations of VAL 2 or more are shown as yellow hatches (May 6-Nov. 20 for 2015 and May 19-Oct. 9 for 2019) and durations of volcanic unrest defined as periods of baseline increase are shown as blue hatches (December 1, 2012-March 1, 2013, April 1-August 1 of 2015, May 1-Nov 1 of 2017 and March 1-August 1 of 2019)

\section{The 2015 eruption and unrest}

The time sequence of the 2015 unrest and eruption of Hakone volcano was already summarized by Mannen et al. (2018). Here, we briefly review this event. The onset of the 2015 unrest was first recognized in early April from increases in DLFs and the baseline length across the volcano detected by GNSS, which were interpreted as inflation of a magma chamber due to addition of magma or magmatic fluid (Harada et al. 2018; Mannen et al. 2018; Yukutake et al. 2019) (Fig. 3). Then, an earthquake swarm, a blowout of SPW39, and an increase in the $\mathrm{CO}_{2} / \mathrm{H}_{2} \mathrm{O}$ ratio of the fumarole gas emitted near the future eruption center followed (Mannen et al. 2018; Ohba et al. 2019). Although the seismicity and the $\mathrm{CO}_{2} / \mathrm{H}_{2} \mathrm{O}$ ratio began decreasing after mid-May, a small phreatic eruption occurred on the morning of June 29 and lasted until the early morning of July 1 (Yukutake et al. 2017; Mannen et al. 2018). The eruption was seemingly triggered by the formation of an open crack in the morning of June 29 near the surface (830-854 $\mathrm{m}$ above sea level) to deeper than $530 \mathrm{~m}$ above sea level as indicated by satellite InSAR and analysis of data obtained from broadband seismometers and tilt meters (Honda et al. 2018; Doke et al. 2018). However, chemical and component analyses of the erupted ash and water indicated a shallow (shallower than $850 \mathrm{~m}$ above sea level or $150 \mathrm{~m}$ deep from the surface) origin (Mannen et al. 2019). Even after the eruption, shallow and deep inflation $(0.8 \mathrm{~km}$ and $-6.5 \mathrm{~km}$ above sea level, respectively) continued without a significant change in the inflation rate until August (Harada et al. 2018). The seismicity began in the central part of the caldera and then propagated to the peripheral areas (Fig. 4a).

\section{The 2017 unrest episode}

The 2017 unrest of Hakone volcano was subtle to detect based on seismicity. Seismicity rates in 2017 were generally low and only 242 earthquakes were detected in the Hakone area by the routine analysis of Hot Springs Research Institute. This annual number is within the range of that in an ordinary year without volcanic unrest after 2000 (Fig. 5). However, slight increases of seismicity were observed in mid-April and early May at sea level beneath Mt. Kintoki at the northern rim of the caldera (A in Fig. 4b). Concurrently, in early May, the baseline length crossing Hakone volcano began to increase slowly and continued to increase until early November (Fig. 3), which can be interpreted as a deep inflation event. Daita et al. (2019) reported an increase in the $\mathrm{CO}_{2} / \mathrm{H}_{2} \mathrm{~S}(\mathrm{C} / \mathrm{S})$ ratio of fumarole gas in Kamiyu, a steaming area north of Owakudani. Previous increases in the $\mathrm{C} / \mathrm{S}$ ratio have been observed accompanying volcanic unrest; however, this increase in the $\mathrm{C} / \mathrm{S}$ ratio was not sharp and did not attenuate swiftly, unlike the increases in the $\mathrm{C} / \mathrm{S}$ ratio accompanying the 2013 and 2015 unrest episodes (Daita et al. 2019; Ohba et al. 2019) (Fig. 3). An increase in DLF events was also observed in early April (Fig. 3).

\section{The 2019 unrest episode}

The 2019 unrest episode at Hakone volcano appears to have begun with a slight increase in seismicity in March, which lasted until the end of October. The sudden onset of a seismic swarm occurred on May 18 beneath the western caldera rim (B in Fig. 4c). Although the location of swarm events was remote from Owakudani $(3 \mathrm{~km}$ west and outside of the latest eruption centers), the number of earthquakes exceeded a set criterion and the Japan Meteorological Agency (JMA), which is in charge of volcano monitoring and alerting, announced a rise in Volcano Alert Level (VAL) from 1 to 2 for the volcano in the early morning of May 19. VAL 2 remained in place until October 7 . The baseline length crossing Hakone volcano began to increase in mid-March and continued until the beginning of August. The $\mathrm{C} / \mathrm{S}$ ratio of Kamiyu also began to increase after the end of April; however, the increase in $\mathrm{C} / \mathrm{S}$ ratio was not sharp and again did not attenuate quickly, similar to the 2017 unrest episode (Fig. 3). During the volcanic unrest, ratios of magmatic gases such 


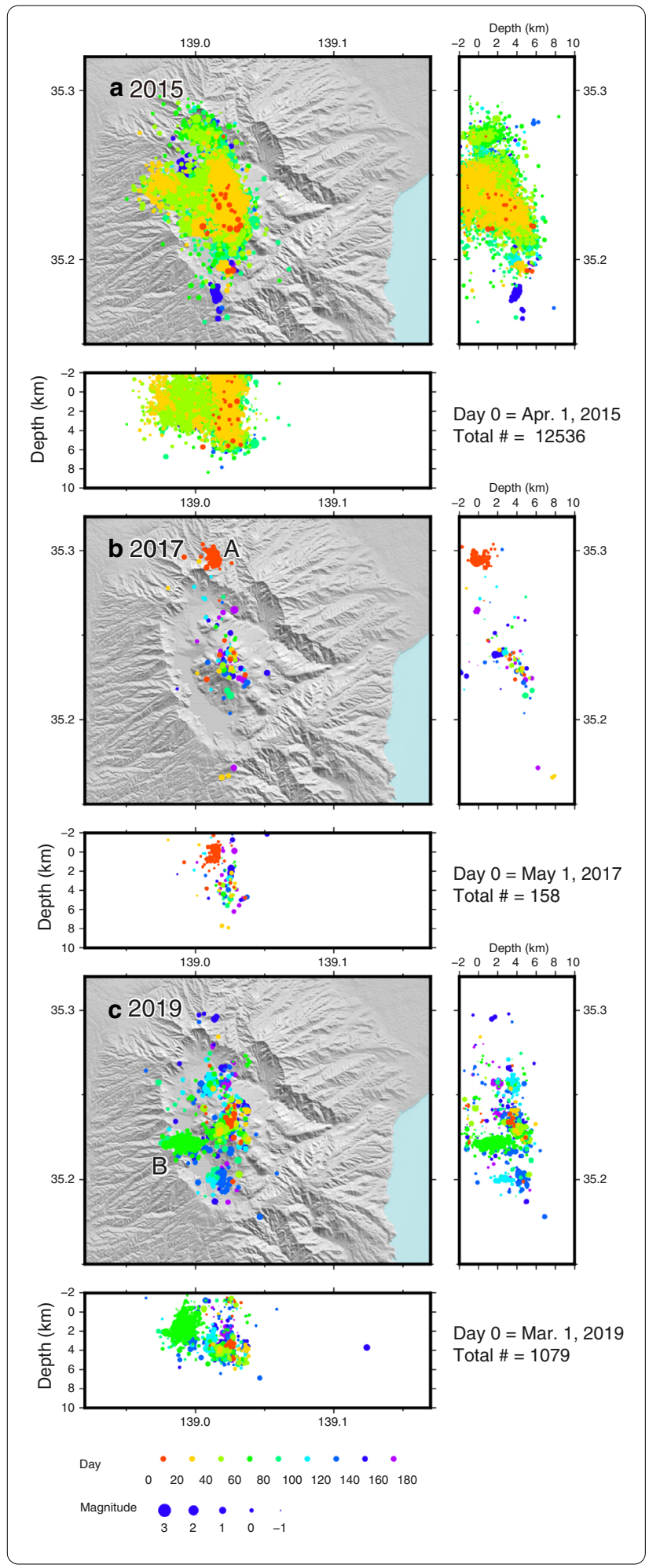

Fig. 4 Maps of hypocenters of volcano-tectonic earthquakes during the co-eruptive (2015) and post-eruptive (2017 and 2019) volcanic unrest episodes. Day 0 is set to the first day of a month during which onset of the edifice inflation was observed and shown in the bottom-right corner of each panel. Hypocenters of earthquakes that occurred within 180 days after day 0 are plotted. Colors indicate days after day 0 and the radius of each circle indicates magnitude of the earthquake. The total number of earthquakes during the 180 days are shown in the bottom-right corner of each panel. A in b) indicates the earthquake swarm in early May in 2017. B in c) indicates the swarms on 18 and 19 of May in 2019

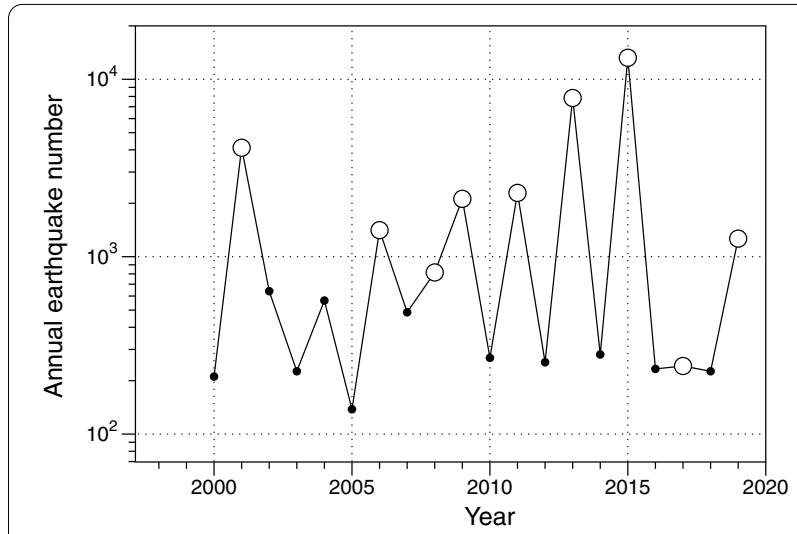

Fig. 5 Annual number of volcano-tectonic earthquakes in Hakone volcano detected by routine analysis of Hot Springs Research Institute of Kanagawa Prefecture. Open circles indicate years that underwent volcanic unrest, while dots indicate years without unrest

as $\mathrm{SO}_{2}$ and $\mathrm{HCl}$ relative to $\mathrm{H}_{2} \mathrm{~S}$, which is a hydrothermal gas, increased significantly in Owakudani, although a significant net increase in magmatic gas was not observed by a Differential Optical Absorption Spectroscopy (DOAS) campaign, as discussed later. A slight increase in DLF events at the beginning was also observed during the unrest; however, interestingly, a far larger number of DLFs was observed in the latest phase of the unrest in late October (Fig. 3).

\section{Data}

\section{Field surveys after the eruption}

Since the entry of researchers around the eruption center was allowed after the 2015 eruption (beginning in March 2016), we have monitored fumarole temperature and chemical compositions of volcanic gases and hot spring waters. Here, we summarize these results. 


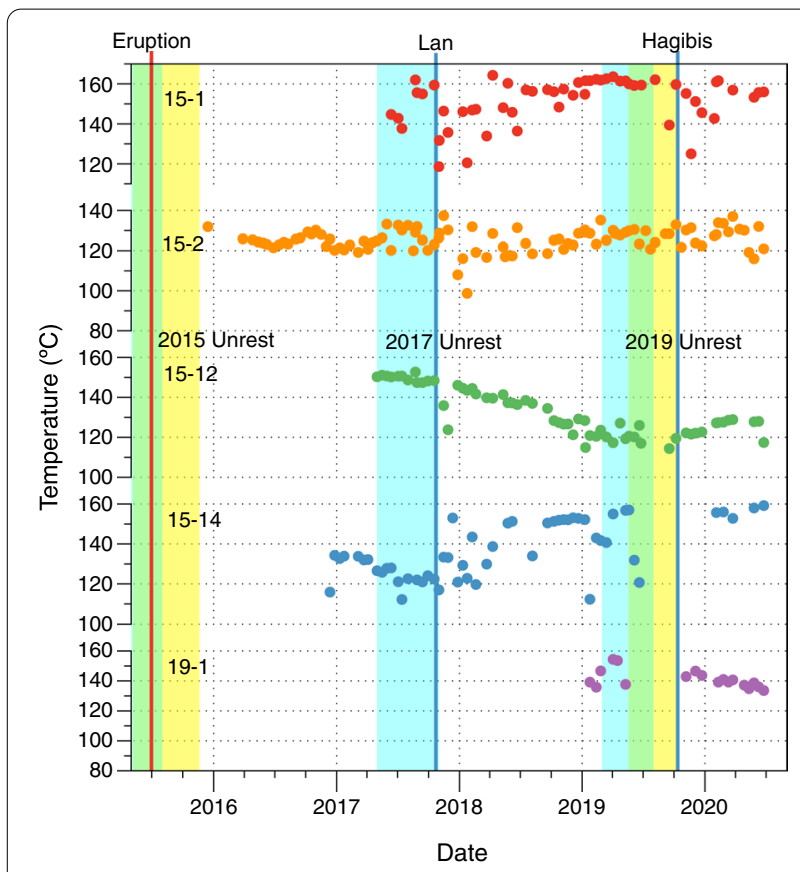

Fig. 6 Temporal changes in temperature of steam emitted from fumaroles in Owakudani. The durations of volcanic unrest episodes are shown as shaded yellow (VAL2 or more) and blue (baseline across the volcano is increasing). See caption of Fig. 3 for details. Timing of heavy rains due to typhoons, which seem to have temporarily lowered steam temperature from some fumaroles, is also shown (Lan on October 23 in 2017 and Hagibis on October 18, 2019). The location of fumaroles is shown in Fig. $1 \mathrm{C}$

\section{Fumarole temperature}

New fumaroles, which emit super-heated steam $(>100$ $\left.{ }^{\circ} \mathrm{C}\right)$, were created in the eruption center area in 2015 . Most of them were formed during the eruption but some formed during the unrest phase before the eruption or even long after the eruption. Up until present, steam temperatures have been routinely measured for at least 20 fumaroles, five of which are relatively active and long-lived and are shown in Fig. 6 (see Fig. 1c for the locations). The maximum measured temperature among them $\left(164.3{ }^{\circ} \mathrm{C}\right)$ was recorded on April 10, 2018 at fumarole $15-1$, which is the fumarole created in the main crater formed during the eruption (Mannen et al. 2019). As shown in Fig. 6, steam temperatures have not decreased for all fumaroles. However, a decline of the maximum measured temperature in the steaming area is detected, at a rate of $\sim 7.7^{\circ} \mathrm{C} / \mathrm{yr}$, using infrared images of the whole area taken continuous since early 2016 (Harada 2018). These observations imply a waning trend in thermal activity in the eruption center area as a whole, while several stable fumaroles constantly emit super-heated steam from depth (probably 150 m deep; Mannen et al. 2019). It is noteworthy that no temperature change related to

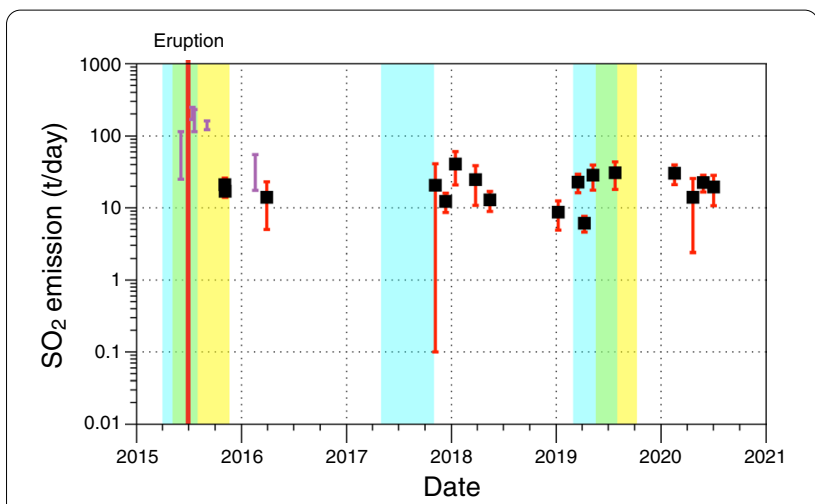

Fig. 7 Sequential change of $\mathrm{SO}_{2}$ emission from Owakudani steaming area (after Abe et al, 2018). Black squares with error bars indicate measurements by Meteorological Research Institute $(2015,2016)$ and Hot Springs Research Institute of Kanagawa Prefecture (after 2017), while others (error bars only) are measurements by JMA

the volcanic unrest in 2017 and 2019 was apparent from these observations.

\section{$\mathrm{SO}_{2}$ emission from Owakudani steaming area}

We conducted DOAS surveys to quantify emission rates of $\mathrm{SO}_{2}$ from the Owakudani steaming area (Abe et al. 2018; Fig. 7). $\mathrm{SO}_{2}$ emission from Owakudani reached more than $100 \mathrm{t}$ /day just after the 2015 eruption; however, the emission rate decreased rapidly and is now estimated to be approximately $10 \mathrm{t} /$ day. The DOAS measurements contain large errors (up to $2-8 \mathrm{t} /$ day) and no significant increase in $\mathrm{SO}_{2}$ during volcanic unrest episodes in 2017 and 2019 was measured.

\section{Fumarole gas}

An accurate chemical analysis of volcanic gas requires meticulous sampling and complicated lab procedures (Ozawa 1968), limiting the monitoring frequency. We, thus, launched a long-term test of simple gas measurements using a detector tube named Passive Dosi-tube (GASTEC 2018). Passive Dosi-tube was originally developed to measure personal exposure to gas in the workplace and obtain time averaged gas concentration in the environment for a prolonged time $(1-10 \mathrm{~h})$. For this study, two sets of dosi-tubes composed of $\mathrm{H}_{2} \mathrm{~S}, \mathrm{SO}_{2}$ and $\mathrm{HCl}$ sensors (GASTEC No. 5D, 4D and $14 \mathrm{D}$, respectively) were installed near $(2-4 \mathrm{~m})$ the vent of fumarole 15-2 (Fig. 1c) for 1 to $2 \mathrm{~h}$. A set of dosi-tubes is directly exposed to the air while another set is installed in a $500 \mathrm{ml}$ ventilated container filled with silica gel granules $(150 \mathrm{~g})$ to prevent condensation of water in and around the dosi-tubes. The dosi-tubes were expected to measure 


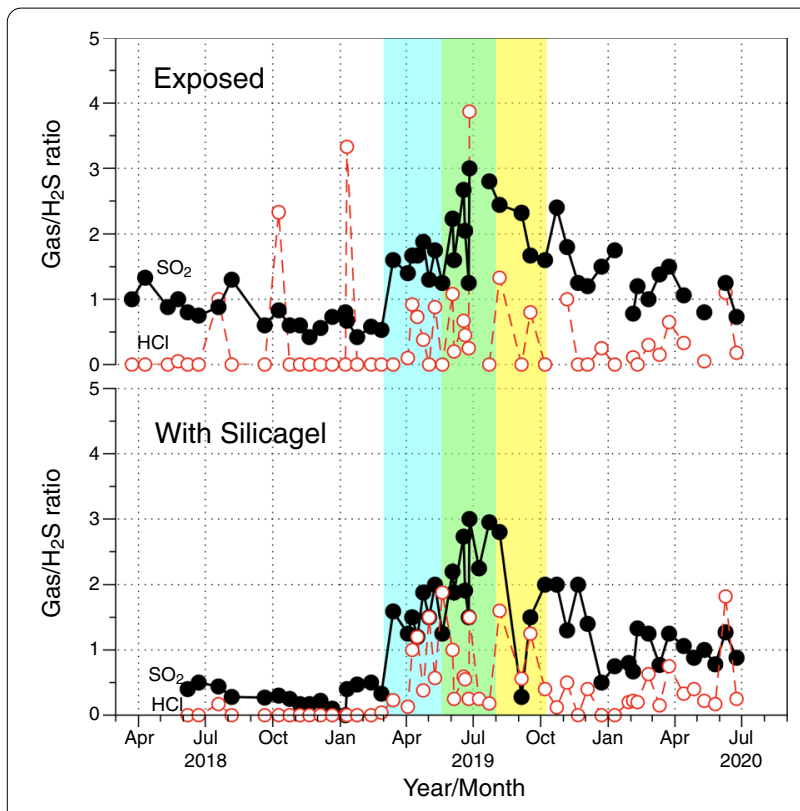

Fig. 8 Sequential change of magmatic components $\left(\mathrm{SO}_{2}\right.$ and $\left.\mathrm{HCl}\right)$ relative to a hydrothermal component $\left(\mathrm{H}_{2} \mathrm{~S}\right)$ within the atmosphere near the 15-2 fumarole, measured by dosi-tubes. Each panel shows values obtained by a set of dosi-tubes exposed to the air (upper panel) and another set within a container filled with silica gel (lower panel). The durations of volcanic unrest episodes are shown as shaded yellow (VAL2 or more) and blue (baseline across the volcano is increasing). See caption of Fig. 3 for details. The spikes in $\mathrm{HCl} / \mathrm{H}_{2} \mathrm{~S}$ ratio of the exposed set $\left(\mathrm{HCl} / \mathrm{H}_{2} \mathrm{~S}>2\right)$ are considered to be errors caused by color changes due to steam precipitation within the tube

ratios of volcanic gas in the atmosphere near the fumarole rather than a direct measurement of steam emitting from the volcano; thus, the observed ratio may be altered by processes in the atmosphere such as gas absorption by water droplets in the steam. However, we aimed to monitor obvious sequential changes in gas ratios with high frequency measurements. Since the dosi-tube measures the volume fraction of the target gas in the atmosphere, the gas ratio is a volumetric ratio and molar ratio assuming an ideal gas. The sequential change of $\mathrm{SO}_{2} / \mathrm{H}_{2} \mathrm{~S}$ and $\mathrm{HCl} / \mathrm{H}_{2} \mathrm{~S}$ ratios, both of which indicate the ratio of magmatic gas to hydrothermal gas, are shown in Fig. 8. Since the start of monitoring (in March 2018), $\mathrm{SO}_{2} / \mathrm{H}_{2} \mathrm{~S}$ ratios show a constant decrease, and $\mathrm{HCl}$ remained nearly undetected until March 2019. However, both $\mathrm{SO}_{2} / \mathrm{H}_{2} \mathrm{~S}$ and $\mathrm{HCl} / \mathrm{H}_{2} \mathrm{~S}$ ratios started to increase after March 2019 and peaked around June 2019. Since then, both $\mathrm{SO}_{2} / \mathrm{H}_{2} \mathrm{~S}$ and $\mathrm{HCl} / \mathrm{H}_{2} \mathrm{~S}$ ratios showed a gradual decline; however, both ratios are still higher than those before March 2019 at the time of writing (mid 2020).

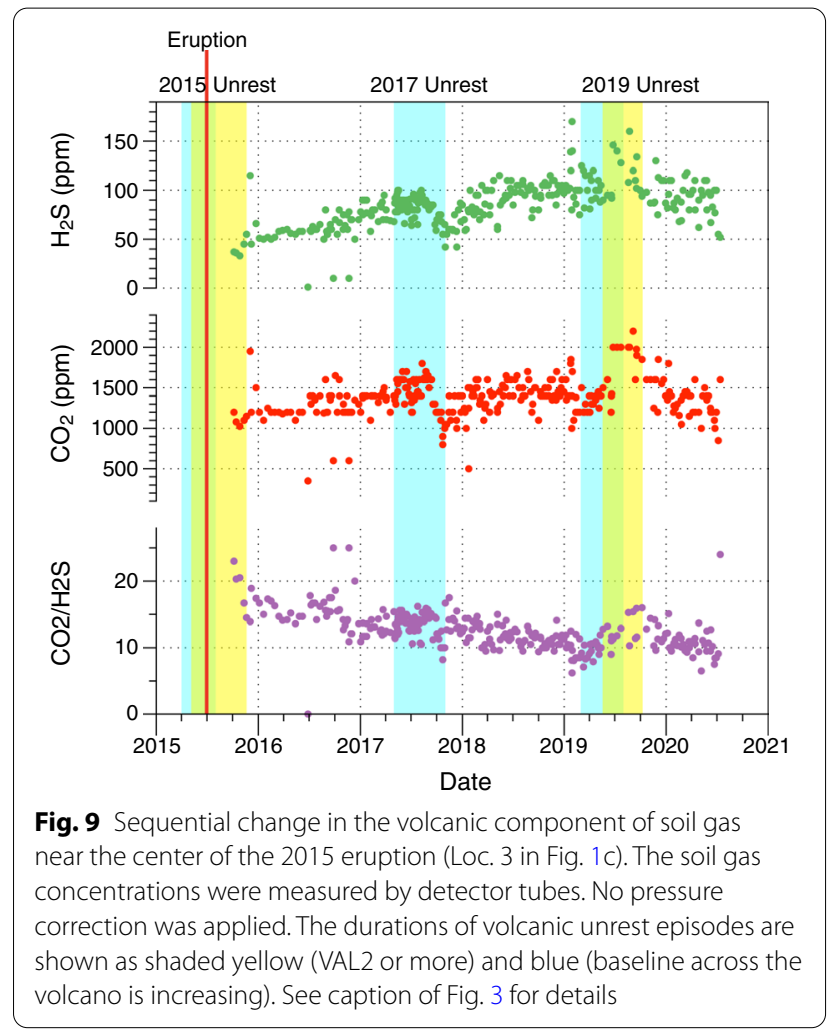

\section{Soil gas}

Near the Owakudani steaming area, volcanic gas is seeping out from the soil under a building floor (Loc. 3 in Fig. 1c). We made weekly measurements of $\mathrm{CO}_{2}$ and $\mathrm{H}_{2} \mathrm{~S}$ in the ventilated air from under the building floor using standard detector tubes since the end of the eruption (Fig. 9). The detector tubes used are GASTEC $2 \mathrm{LC}\left(\mathrm{CO}_{2}\right)$ and $4 \mathrm{~L}\left(\mathrm{H}_{2} \mathrm{~S}\right)$. Since the volcanic gas emitted from soil is not affected by nearby rainfall, and the building ventilation system enables almost constant flux of air from the subfloor, we can expect stable measurements of emitted gas. The soil gas shows a constant increasing in $\mathrm{H}_{2} \mathrm{~S}$, while $\mathrm{CO}_{2}$ remains almost stable. Interestingly, both $\mathrm{H}_{2} \mathrm{~S}$ and $\mathrm{CO}_{2}$ show subtle increases during the 2017 and 2019 unrest episodes. The $\mathrm{C} / \mathrm{S}\left(=\mathrm{CO}_{2} / \mathrm{H}_{2} \mathrm{~S}\right)$ ratio decreased almost constantly after the 2015 eruption; however, slight increases can be recognized during the 2017 and 2019 unrest episodes.

\section{Artificial hot springs}

In Owakudani, artificial hot springs (AHS) have been created by mixing steam from SPW and spring water pumped up from the caldera floor to supply the local 


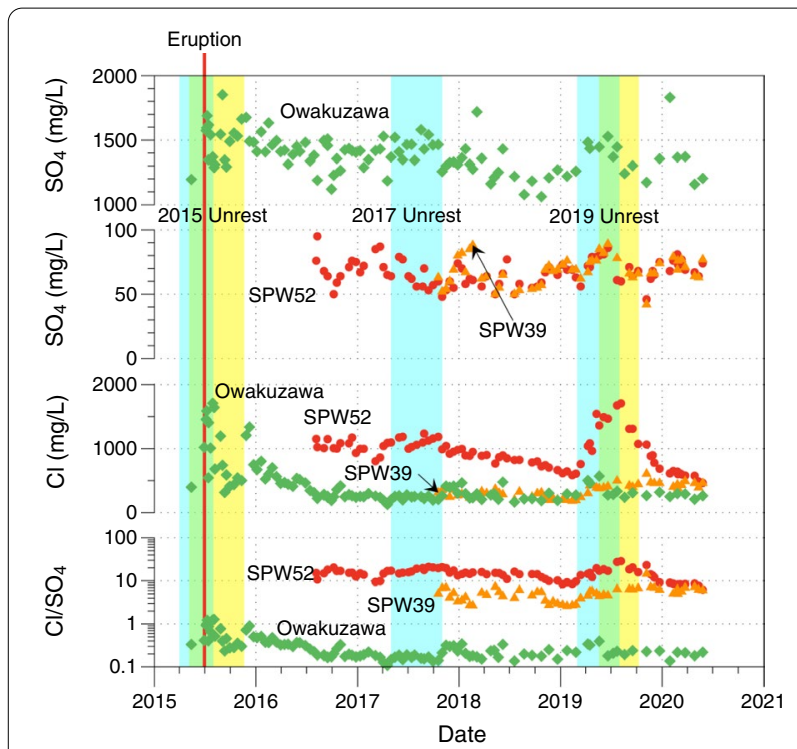

Fig. 10 Sequential changes in the chemistry of artificial hot springs created by the steam from SPW52 (red circle) and SPW39 (orange triangle), and water from the Owakuzawa river (green diamond)

hotel industry (Mannen et al. 2019). AHS is not a diluted condensation of steam from the production well because less-soluble gases such as $\mathrm{CO}_{2}$ and $\mathrm{H}_{2} \mathrm{~S}$ are barely absorbed in the water; however, its chemistry can be useful to monitor the hydrothermal system beneath the steaming area. We routinely analyzed the chemistry of AHSs from SPWs 39 and 52 (Fig. 1c). Here, we show temporal changes of $\mathrm{Cl}$ and $\mathrm{SO}_{4}$ content, which are possibly magmatic in origin, and major anions in the AHSs (Fig. 10).

SPW52, which is $500 \mathrm{~m}$ deep and the well that blew out during the 2001 unrest, had shown a continuous decrease in $\mathrm{Cl}$ of the AHS since the beginning of monitoring; however, after early April just before the onset of the 2017 unrest, $\mathrm{Cl}$ content spiked. The $\mathrm{Cl}$ content again showed a constant decrease after the end of the 2017 unrest, but then increased significantly when the baseline length across Hakone volcano started to increase in early May 2019. The Cl content of SPW39 (413 m deep) also showed an unrest-related increase. For both $\mathrm{AHSs}, \mathrm{SO}_{4}$ changes during the unrest were observed but less significant.

\section{River water from the eruption center}

The entire eruption center area forms the headstream of the Owakuzawa river. Thus, water from Owakuzawa is presumably affected by volcanic gas and natural hot springs within the area, and its chemical components can reflect hydrothermal activity. To obtain water highly affected by the fumarole activity within the eruption center even during severe volcanic unrest, our sampling

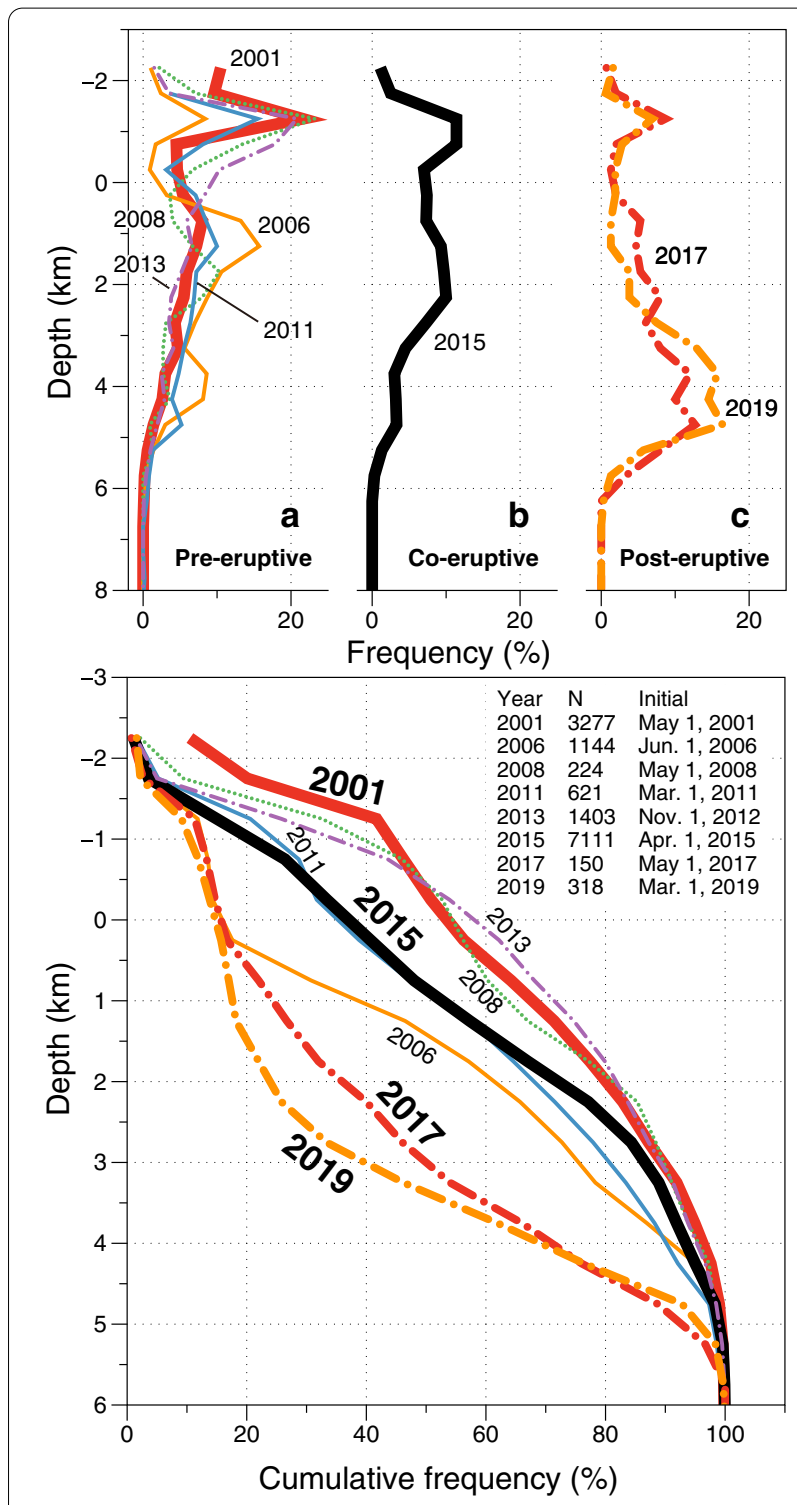

Fig. 11 Frequency-depth variations of volcano-tectonic earthquakes in the hydrothermal system during post-2001 volcanic unrest episodes. Frequencies of every $500 \mathrm{~m}$ depth interval are shown. Upper panels; frequency-depth variations of a) pre- b) co- and c) post-eruptive volcanic unrests. Lower panel d) shows cumulative frequency-depth variations for each volcanic unrest episode. We count the number of earthquakes with epicenters within $2 \mathrm{~km}$

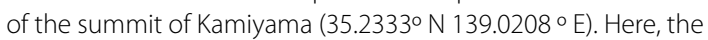
earthquakes during volcanic unrest are defined as those occurring within 6 months of the initial date. The initial dates and total number of earthquakes $(\mathrm{N}$ ) are shown in the upper right of $\mathrm{d}$ ). The hypocenter catalog is obtained by the routine analysis by the Hot Springs Research Institute of Kanagawa Prefecture. Error of hypocenter location is estimated by square of the diagonal element of the error covariance matrix as $0.05 \mathrm{~km}$ (NS), $0.06(\mathrm{EW})$, and $0.14 \mathrm{~km}$ (depth). Note that hypocenter depths for earthquakes shallower than $0 \mathrm{~km}$ are not well constrained 
point was located just outside of the restriction area (at $470 \mathrm{~m}$ downstream of 15-12 fumarole; Fig. 1b; Fig. 2 in Mannen et al, 2018). Indeed, just after the 2015 eruption, water from the river showed a significant increase in $\mathrm{Cl}$ and $\mathrm{SO}_{4}$ (Fig. 10; Mannen et al. 2018). After the eruption, the $\mathrm{Cl}$ and $\mathrm{SO}_{4}$ contents showed constant decline; however, they apparently rose slightly at the beginning of the 2019 unrest. The $\mathrm{Cl}$ and $\mathrm{SO}_{4}$ changes related to the 2017 unrest were ambiguous (Fig. 10).

\section{Seismicity related to volcanic unrest after the $\mathbf{2 0 1 5}$ eruption}

We examined the depth variation of seismic events beneath the 2015 eruption center area to detect any changes related to the eruption. Figure 11 shows the depth variation of earthquakes occurrence within the 2015 eruption center area during volcanic unrest episodes in this century. Interestingly, the seismicity depth change from before and after the eruption seems to be significant. Before the 2015 eruption, hypocenters of more than $60 \%$ of earthquakes in and around the Owakudani steaming area were located shallower than $2 \mathrm{~km}$ depth, while such earthquakes comprise less than $40 \%$ of the total after the eruption. This observation indicates that the fraction of shallower earthquakes declined significantly after the 2015 eruption.

\section{Discussion}

\section{Lowered VT activity and depressurization beneath the 2015 eruption center}

The 2015 eruption appears to have been triggered by inflation at depth as indicated by an increase of baseline length across the volcano (Harada et al, 2018; Kobayashi et al.2018; Mannen et al. 2018) (Fig. 12a, b). Similar deep inflation was also recognized since the earliest phase of the post-eruptive unrest episodes in 2017 and 2019 by GNSS monitoring (Fig. 3). DLFs were also detected in the earliest phase of the pre-, co-, and post-eruptive unrest. However, subsequent seismicity seems to be different for the post-eruptive unrest episodes. VT earthquakes beneath the central cone were not as prevalent during the post-eruptive unrest episodes, especially in the shallow region (Figs. 4 and 11), although significant seismic activity took place beneath the caldera rim, remote from the active fumarole (A and B in Fig. 4). Assuming pore pressure increase is the trigger for VT seismicity (Yukutake et al. 2011; Mannen et al. 2018), such a significant difference can be interpreted as lower pore pressure rise in the hydrothermal system beneath the central cone, especially in the shallower part of the system $(<4 \mathrm{~km}$ deep). The insufficient pressurization of the hydrothermal system beneath the central cone compared with the pre-eruptive unrest episodes can be explained by the destruction of the cap-rock of the volcano by the 2015 eruption (Fig. 12c and d).

Mannen et al (2019) concluded that the materials erupted in the 2015 eruption were derived from caprock (from surface to $100 \mathrm{~m}$ deep) based on geological and magnetotelluric analyses. The enthalpy of the maximum temperature of steam emitted from the fumarole $\left(2805 \mathrm{~kJ} / \mathrm{kg}, 164.3^{\circ} \mathrm{C}\right.$ at the surface; Fig. 6) is very close to that of saturated steam coexisting with liquid water at $200{ }^{\circ} \mathrm{C}$ and $\sim 1.5 \mathrm{MPa}$, which is a hydrothermal condition at the depth of $150 \mathrm{~m}$ assuming hydrostatic pressure. Magnetotelluric surveys and InSAR analysis indicate that a vapor-rich portion of the hydrothermal system is located approximately $150 \mathrm{~m}$ below the surface of the eruption center and named the portion 'vapor pocket' (Kobayashi et al. 2018; Doke et al. 2018; Mannen et al. 2019). This line of evidence implies that the 2015 eruption tapped vapor from the uppermost part of the hydrothermal system and some vapor routes through the cap-rock created by the eruption are still alive as indicated by surviving high temperature fumaroles $(\geq 160$ $\left.{ }^{\circ} \mathrm{C}\right)$. Such degassing routes after the eruption can inhibit pressurization of the hydrothermal system during an unrest episode. The higher resistivity of the enlarged vapor pocket after the eruption (Mannen et al. 2019) indicates an increase in the vapor phase, presumably due to depressurization caused by the breach of the cap-rock (Fig. 12c). Also, the intensive seismic and hydrothermal activities during the 2015 activity may have increased the permeability of the hydrothermal system beneath Owakudani and contributed to the inhibition of pressure increase in the region during the post-eruptive unrest (Sibson et al. 1975).

Even though the eruption breached the cap-rock beneath Owakudani, pore pressure seems to have increased in other parts of the hydrothermal system during the post-eruptive unrest episodes. The seismic swarm beneath the northern (2017; A in Fig. 4b) and western (2019; B in Fig. 4c) caldera rim during the unrest episodes could be the manifestation of fluid injection from depth to a separated part of the hydrothermal system that caused a pore pressure rise and fluid migration as observed in the previous unrest (Yukutake et al. 2011), although a detailed analysis remains yet to be done (Fig. 12d).

Doke et al. (2020) detected a contraction source in the west of Owakudani using InSAR time series analysis, which is distinct from the vapor pocket beneath the eruption center. This result implies that the hydrothermal system beneath the central cone of Hakone volcano is not a single large expanse as implied from the resistivity structure (Yoshimura et al, 2018), which is highly 


\section{a Pre-eruptive quiescence}

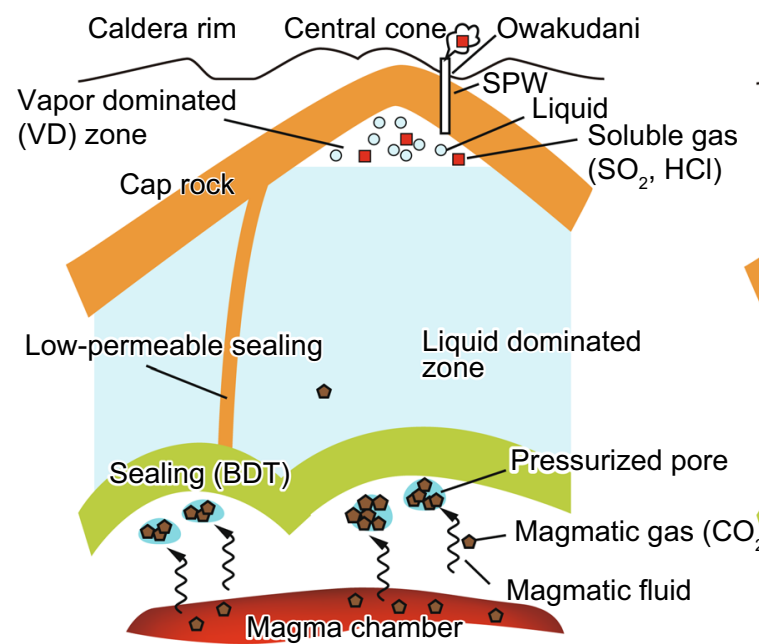

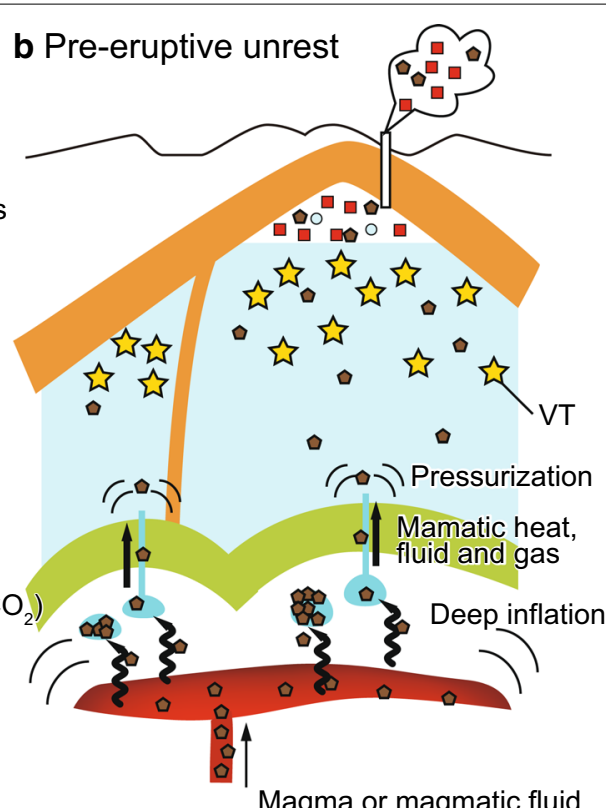

Magma or magmatic fluid
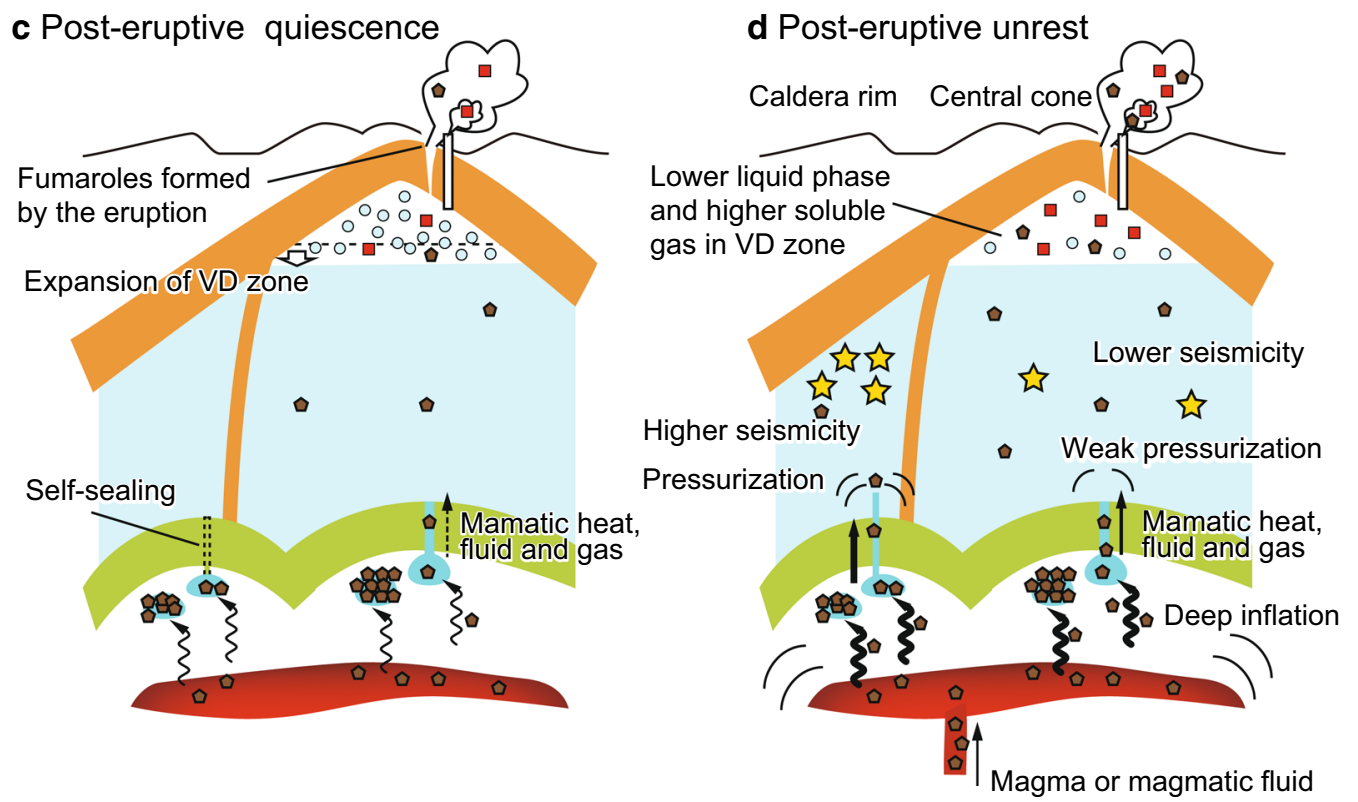

Fig. 12 Schematic model of the pre- and post-eruptive hydrothermal systems. Not drawn to scale. See text for depth and dimension of the features. a) Before the 2015 eruption, cap-rock and sealing at the brittle-ductile transition (BDT) were intact and magmatic gas accumulated within the pressurized pores beneath the BDT. We assume individual hydrothermal systems beneath the central cones and caldera rim are separated by a low-permeable sealing. b) Ruptures of sealing at the BDT induced by a deep inflation event allowed rapid migration of accumulated heat, fluid and pore pressure beneath the BDT to the liquid-dominated zones of the hydrothermal systems. Volcano-tectonic earthquakes (VTs) and steaming from the steam production wells (SPW) increased due to the pressurization of the hydrothermal system. c) The 2015 eruption formed paths for steam from the vapor-dominated (VD) zone to the surface. Due to the path, the post-eruptive hydrothermal system beneath the central cone was depressurized and volume of the VD zone increased. The rupture of seals at the BDT healed beneath the caldera rim, but were maintained beneath the central cones, which allows migration of heat and pore fluid beneath the BDT. d) Post-eruptive unrest episodes were also triggered by deep inflation event. Beneath the central cones, no extensive pressurization of the hydrothermal system occurs because pores beneath the BDT were not pressurized due to the rupturing in the 2015 eruption. Heat migration from deep to shallow lowered the liquid phase fraction within the VD zone and caused less effective scrubbing, which allowed enrichment of soluble gas $\left(\mathrm{SO}_{2}\right.$ and $\left.\mathrm{HCl}\right)$ within the steams from the VD zone and fumaroles. Magmatic $\mathrm{CO}_{2}$ within the fumaroles also rose, but not significantly due to no release of accumulated $\mathrm{CO}_{2}$ within the pressurized pores beneath the BDT 
interconnected. We, thus, need to assume a complex of multiple hydrothermal sub-systems separated by lowpermeable seals, and each sub-system hosts a localized earthquake swarm as observed in the previous unrest episodes (Fig. 12).

\section{Increase of magmatic gas during the post-eruptive unrest}

During the post-eruptive unrest episodes, magmatic gas species, such as $\mathrm{SO}_{2}, \mathrm{HCl}$ and $\mathrm{CO}_{2}$ were observed to increase compared to $\mathrm{H}_{2} \mathrm{~S}$, which is a representative hydrothermal gas (Figs. 3, 8 and 9). The net increase of $\mathrm{HCl}$ emission during the post-eruptive unrest periods is also implied from river water chemistry and an increase of $\mathrm{HCl}$ in the vapor pocket beneath Owakudani was indicated by the chemistry of AHSs generated from SPWs (Fig. 10). Since $\mathrm{HCl}$ tends to be degassed from shallow magma (Rouwet et al. 2017), this might suggest intrusion and degassing of shallow magma during the post-eruptive unrest. However, no indication of shallow intrusion, such as low frequency earthquakes and harmonic tremor, was observed in our geophysical monitoring. Also, our DOAS survey observed no significant gross increase in $\mathrm{SO}_{2}$ emissions (Fig. 7). The emissions of $\mathrm{SO}_{2}$ during the post-eruptive unrest episodes were less than the standard criterion to indicate magma involvement $(>100 \mathrm{t} / \mathrm{d}$ ) (Symonds et al. 2001).

$\mathrm{SO}_{2}$ and $\mathrm{HCl}$ are magmatic, but they are highly soluble in liquid water. We, thus, attribute the increase of these gases to a change in liquid-vapor ratio in the uppermost part of the hydrothermal system $(\sim 150 \mathrm{~m}$ deep). In the environment where liquid water exists, $\mathrm{SO}_{2}$ and $\mathrm{HCl}$ can be scrubbed from the coexisting volcanic gas; thus, the increase of these gases can imply drying-out of the hydrothermal system (Symonds et al. 2001). Since the fumarole temperatures showed no significant increase during the post-eruptive unrest episodes (Fig. 6), significant heating of the hydrothermal system that vaporized all liquid water in the shallowest hydrothermal system is highly improbable. Instead, a slight increase of heat flux changed the liquid-vapor ratio in the uppermost part of the hydrothermal system $(\sim 150 \mathrm{~m}$ deep) without any change of temperature in the vapor-liquid coexisting system. The increase of heat flux may be attributed to the injection of hot and pressurized magmatic fluid into the hydrothermal system by the rupture of the sealing zone at depth, possibly at the brittle-ductile transition (Fig. 12c, d).

\section{Previous model of volcanic unrest}

Ohba et al. (2019) proposed another mechanism to explain unrest phenomena at Hakone volcano, which relies on steady degassing of magma rather than newly derived magmatic fluid from depth. They emphasized the increase of atmospheric gases such as Ar and $\mathrm{N}_{2}$ in the fumarole emissions a few months before the onset of the 2015 unrest and interpreted this as the development of a sealing zone between the hydrothermal and magmaperipheral systems. During the pre-unrest phase, a sealing zone developed near the brittle-ductile transition and the pressure of magmatic gas represented by $\mathrm{CO}_{2}$ beneath the sealing zone increased. Meanwhile, pressure in the hydrothermal system dropped due to the lack of magmatic gas influx from the magma-peripheral system, allowing atmospheric gas to seep into the hydrothermal system, as detected by their survey of the fumarole gas.

This is an interesting model that interprets the results of gas monitoring; however, the model neglects geophysical observations such as deep inflation and DLFs in the early phase of the volcanic unrest episodes. If the deep inflation was caused by pressurization of volatile species beneath the sealing zone, deflation should have occurred after the breach of the sealing zone. This means deep deflation should have been observed when VT earthquakes surged. Also, the DLF events in the very early phase of the unrest episodes indicate injection of magma or magmatic fluid from depth. We acknowledge that it is hard to explain the increase of atmospheric species in the fumarole during the pre-unrest phase; however, we point out that this was observed only in fumarole $\mathrm{N}$, which is located near the eruption center of the 2015 eruption. This means that the injection of atmospheric species seems to have occurred only in a very limited part of the hydrothermal system, probably near the surface of the steaming area. In the steaming area, reactivation of an almost extinct steam production well (SPW39) was recognized on April 17 (Mannen et al. 2018) and inflation of the steaming area was recognized by InSAR on May 7 (Doke et al. 2018). These observations indicate that underground fracturing and a local uplift $(\leq 200 \mathrm{~m}$ in diameter) due to very shallow inflation $(\sim 150 \mathrm{~m}$ depth; vapor pocket) could have started before May 2015 (Kobayashi et al. 2018; Doke et al. 2018). Indeed, fracturing of the surface was visually observed after mid-June (Mannen et al. 2018) and such fracturing may have introduced air into the shallowest region of the hydrothermal system near the uplift region.

\section{Degassing of $\mathrm{CO}_{2}$ during the unrest episodes and its implication}

The increase in the $\mathrm{C} / \mathrm{S}$ ratio from the very early phase of the unrest episodes at Hakone volcano can be explained by a breach of the sealing zone that leads to a significant pressure contrast between the hydrothermal system and a $\mathrm{CO}_{2}$ reservoir beneath it. The sealing zone may not be necessarily be identical to the brittle-ductile transition as implied by Ohba et al. (2019). However, it is noteworthy 
that no significant change in $\mathrm{SO}_{2}$ and $\mathrm{H}_{2} \mathrm{~S}$ emission had been recognized in the peripheral fumaroles around the eruption center (Ohba et al, 2019). Also, our DOAS survey implies no significant increase of $\mathrm{SO}_{2}$ emission during the post-eruptive unrest episodes occurred in 2017 and 2019 (Fig. 7). These observations may mean that principally, $\mathrm{CO}_{2}$ was injected into the hydrothermal system, implying magma degassing deeper than the levels of $\mathrm{SO}_{2}$ exsolution but shallower than that of $\mathrm{CO}_{2}$. The breach of the sealing zone and the migration of the hydrothermal fluid from the magma-peripheral to the hydrothermal systems might have accompanied bubbling of $\mathrm{CO}_{2}$ (Lowenstern 2001), although no corresponding geophysical signal was observed.

Degassing from newly derived magmatic fluid may have been the source of the $\mathrm{CO}_{2}$ and the reason for the increase in the $\mathrm{C} / \mathrm{S}$ ratio; however, the 2017 and the 2019 unrest episodes did not show sharp increases in the C/S ratio even though these events were accompanied by DLFs (Fig. 3). Such a difference in the temporal change in the $\mathrm{C} / \mathrm{S}$ ratio during the volcanic unrest episodes indicates a change in physical structure caused by the 2015 eruption. We previously proposed a breach of the shallow cap-rock. In addition to that, we propose a breach of the deep sealing zone during the 2015 eruption, with its annealing process after the eruption still incomplete. Assuming the sealing zone remained breached, volatiles steadily degassed from the magma chamber cannot be stored beneath the sealing zone in large quantity (Fig. 12c). Thus, only newly derived magmatic fluid may contribute to the $\mathrm{CO}_{2}$ rise during the volcanic unrest, and the observed $\mathrm{CO}_{2}$ increase at the surface became subtle as observed during the unrest episodes in 2017 and 2019 (Fig. 12d). Based on this model, we expect that the sequential change of the $\mathrm{C} / \mathrm{S}$ ratio characterized by a strong increase just after the beginning of an unrest and a strong decrease after the climax as observed in 2013 and 2015 (Fig. 3) will resume after a restoration of the sealing zone in the future.

\section{Model caveats}

Deep inflation sources during Hakone unrest episodes have been located using inversion analysis. However, their optimum depths were not unique, ranging from $6.5 \mathrm{~km}$ for the 2015 unrest and eruption (Harada et al. 2018) to $10 \mathrm{~km}$ for the 2019 unrest (Doke et al. 2019). Mannen et al. (2018) interpreted deep inflation during Hakone unrest episodes, as indicated by GNSS data analysis, as magma replenishment. Kobayashi et al. (2018) located the source of the deep inflation during the 2015 unrest and eruption (4.8 km deep) and considered the inflation source to represent a magma chamber. However, these source depths are shallower than Region
1, which is considered to represent a magma chamber from seismic tomography, and are instead located in the hydrothermal system (Yukutake et al. 2015). We may, thus, need to assume magma intrusion or accumulation of magmatic fluid in the deeper part of the hydrothermal system. As discussed above, intrusion of magma to the hydrothermal system is possible, but relatively low emission of magmatic gases observed are seemingly at odds with the model.

Accumulation of magmatic fluid within the deeper part of the hydrothermal system may increase the likelihood of a large phreatic eruption in the future. Post-eruptive deflations, such as those observed after the Ontake eruption in 2014 (Murase et al. 2016; Narita and Murakami 2018) and Te Maari eruption in 2012 (Hamling et al. 2016), indicate accumulation of magmatic fluid before the major phreatic eruption. Such post-eruptive deflation was not observed after the 2015 eruption of Hakone and this could be an alert for a large phreatic eruption in future. Since intrusion of magmatic fluid at depth can occur without significant seismic and geodetic precursors as shown by the 2014 eruption of Ontake (Takagi and Onizawa 2016), we should be alert even to minor volcanic unrest episodes.

\section{Conclusion}

The volcanic unrest episodes of Hakone volcano observed after its latest phreatic eruption in 2015 were reviewed. Like the pre- and co-eruptive unrest, the posteruptive unrest episodes that occurred in 2017 and 2019 were accompanied by inflation of the volcano and deep low frequency events, both of which can be interpreted as a magma replenishment to the deep magma chamber $(\sim 10 \mathrm{~km})$ or injection of magmatic fluid into the bottom of the hydrothermal system $(\sim 6.5 \mathrm{~km})$. Seismicity beneath the 2015 eruption center during the post-eruptive unrest episodes was, however, significantly lower than that of pre- and co-eruptive unrest episodes of the volcano, especially in the shallower portion of the hydrothermal system. Such minimal seismicity can result from a breach of the cap-rock during the 2015 eruption, which inhibited pore pressure accumulation within the hydrothermal sub-system beneath the eruption center area. Accompanying the post-eruptive unrest episodes, increases of magmatic components such as $\mathrm{SO}_{2}, \mathrm{HCl}$ and $\mathrm{CO}_{2}$ relative to a hydrothermal component $\mathrm{H}_{2} \mathrm{~S}$ of fumarole gas were observed. Amounts of $\mathrm{Cl}$ in an artificial hot spring generated by steam from deep steam production wells and river water were found to have increased. Intrusion of magma to shallow depth is, however, improbable given the stable fumarole temperature, the lack of nontectonic earthquakes (low frequency event and harmonic tremor), and limited $\mathrm{SO}_{2}$ emission $(<100 \mathrm{t} / \mathrm{d})$. Instead, 
the increased proportion of magmatic gas $\left(\mathrm{SO}_{2}\right.$ and $\left.\mathrm{HCl}\right)$ relative to the hydrothermal gas $\left(\mathrm{H}_{2} \mathrm{~S}\right)$ during the 2019 unrest implies depletion of the liquid phase in the shallowest portion of the vapor-liquid coexisting hydrothermal system due to the increased heat flux from depth.

The sealing zone of the volcano, presumably located near the brittle-ductile boundary, also seems to have been breached by the 2015 eruption as no sharp rise in the $\mathrm{C} / \mathrm{S}$ ratio of the fumarole gas was observed during the post-eruptive unrest episodes. The sharp rise of the $\mathrm{C} / \mathrm{S}$ ratio can be interpreted as a release of $\mathrm{CO}_{2}$ that had accumulated beneath the sealing zone. We, thus, anticipate re-establishment of the temporal $\mathrm{C} / \mathrm{S}$ change as seen during the pre-eruptive unrest episodes after the complete re-establishment of the sealing zone. The rupture of cap-rock by the 2015 eruption may lower the possibility of future phreatic eruptions originating from the shallow hydrothermal system; however, accumulation of magmatic fluid in the deeper part of the hydrothermal system cannot be ruled out, and the possibility of a future large phreatic eruption cannot be eliminated.

\section{Abbreviations}

BDT: Brittle-ductile transition; CSAMT: Controlled source audio-frequency magnetotelluric; DLF: Deep low frequency events; DOAS: Differential optical absorption spectrometry; InSAR: Interferometric synthetic-aperture radar; JMA: Japan Meteorological Agency; SPW: Steam production well for making hot spring water in Owakudani.; VAL: Volcano Alert Level; VT: Volcano-tectonic.

\section{Acknowledgements \\ Hakone Town Office and Hakone Onsen Kyokyu Co. Ltd helped with our field survey. Takeshi Ohba at Tokai University kindly offered his volcanic gas data. Hakone Geomuseum kindly provided their gas data of the Loc. 3. This manuscript was greatly improved by helpful English editing by Diana Roman (Carnegie Institution for Science) and Christopher Conway (Geological Survey of Japan). The authors are grateful for the insightful comment and suggestions made by two anonymous reviewers and the handling editor.}

\section{Authors' contributions}

KM engaged in geological observation and drafted the manuscript compiling multidisciplinary data. YD has routinely measured $C / S$ ratio of volcanic gas. YA and $\mathrm{MH}$ conducted DOAS surveys. MH and RD analyzed GNSS data. GK, YM and $\mathrm{NH}$ implemented sampling and chemical analysis of waters. YY analyzed DLF. All authors reviewed and approved the final manuscript. All authors read and approved the final manuscript

\section{Funding}

This study was implemented as an ordinary research project of HSRI.

\section{Availability of data and materials}

The datasets that were used to create figures in this paper appear in Supplementary Information before the publication.

\section{Declarations}

Ethics approval and consent to participate

Not applicable.

\section{Consent for publication}

Not applicable.

\section{Competing interests}

The authors declare that they have no competing interests.

\section{Author details}

${ }^{1} 586$ Iriuda, Odawara, Kanagawa 250-0031, Japan. ${ }^{2}$ 1-3-39 Shinomiya, Hiratsuka, Kanagawa 254-0014, Japan. ${ }^{3}$ 1-2-1 Misaki, Niigata 950-0954, Japan.

Received: 28 September 2020 Accepted: 22 February 2021

Published online: 26 March 2021

\section{References}

Abe Y, Harada M, Itadera K, Mori T, Takagi A (2018) Emission rate of sulfur dioxide at Owakudani, Hakone volcano, Japan - Observation, analysis, and temporal transition of emission rate to June 2018. Bull Hot Springs Res Inst Kanagawa Prefect 50:1-18 (in Japanese with English abstract)

Daita Y, Ohba T, Yaguchi M, Sogo T, Harada M (2019) Temporal variation of the fumarolic gas composition (C/S ratio) in 2017 at north side slope of Owakudani geothermal area, Hakone volcano. Bull Hot Springs Res Inst Kanagawa Prefect 51:37-44 (in Japanese)

Doke R, Harada M, Itadera K, Kato T (2019) Crustal deformation associated with the 2019 earthquake swarm activity of Hakone volcano observed by GNSS. Bull Hot Springs Res Inst Kanagawa Prefect 51:1-9 (in Japanese)

Doke R, Harada M, Mannen K, Itadera K, Takenaka J (2018) InSAR analysis for detecting the route of hydrothermal fluid to the surface during the 2015 phreatic eruption of Hakone Volcano. Japan Earth Planets Space 70:63. https://doi.org/10.1186/s40623-018-0834-4

Doke R, Kikugawa G, Itadera K (2020) Very Local Subsidence Near the Hot Spring Region in Hakone Volcano, Japan, Inferred from InSARTime Series Analysis of ALOS/PALSAR Data. Remote Sensing 12(17):2842. https://doi. org/10.3390/rs12172842

GASTEC (2018) GASTEC Handbook: Environmental analysis technology, 18th edn. GASTEC, Ayase

Hamling IJ, Williams CA, Hreinsdõttir S (2016) Depressurization of a hydrothermal system following the August and November 2012 Te Maari eruptions of Tongariro, New Zealand. Geophys Res Lett 43:168-175. https://doi.org/ 10.1002/2015GL067264

Harada M (2018) Characteristics of continuous observation by infrared thermal camera at Owakudani, Hakone volcano. Bull Hot Springs Res Inst Kanagawa Prefect 50:53-59 (in Japanese)

Harada M, Doke R, Mannen K, Itadera K, Satomura M (2018) Temporal changes in inflation sources during the 2015 unrest and eruption of Hakone volcano. Japan Earth Planets Space 70:152. https://doi.org/10.1186/ s40623-018-0923-4

Honda R, Yukutake Y, Morita Y, Sakai S, Itadera K, Kokubo K (2018) Precursory tilt changes associated with a phreatic eruption of the Hakone volcano and the corresponding source model. Earth Planets Space 70:63. https://doi. org/10.1186/s40623-018-0887-4

Honda R, Yukutake Y, Yoshida A, Harada M, Miyaoka K, Satomura M (2014) Stress-induced spatiotemporal variations in anisotropic structures beneath Hakone volcano, Japan, detected by S wave splitting: A tool for volcanic activity monitoring. J Geophys Res Solid Earth 119:7043-7057. https://doi.org/10.1002/2014JB011151

Kobayashi T, Morishita Y, Munekane H (2018) First detection of precursory ground inflation of a small phreatic eruption by InSAR. Earth Planet Sci Lett 491:244-254. https://doi.org/10.1016/..epsl.2018.03.041

Lowenstern JB (2001) Carbon dioxide in magmas and implications for hydrothermal systems. Miner Depos 36:490-502. https://doi.org/10.1007/s001260100185

Mannen K, Tanada T, Jomori A, Akatsuka T, Kikugawa G, Fukazawa Y, Yamashita H, Fujimoto K (2019) Source constraints for the 2015 phreatic eruption of Hakone Volcano, Japan, based on geological analysis and resistivity structure. Earth Planets Space 71:135. https://doi.org/10.1 186/s40623-019-1116-5

Mannen K, Yukutake Y, Kikugawa G, Harada M, Itadera K, Takenaka J (2018) Chronology of the 2015 eruption of Hakone volcano, Japan - geological background, mechanism of volcanic unrest and disaster mitigation measures during the crisis. Earth, Planets Sp 70:68. https://doi.org/10. 1186/s40623-018-0844-2

Miyagi I, Geshi N, Hamasaki S, Oikawa T, Tomiya A (2020) Heat source of the 2014 phreatic eruption of Mount Ontake. Japan Bull Volcanol 82:33. https://doi.org/10.1007/s00445-020-1358-x 
Murase M, Kimata F, Yamanaka Y, Horikawa S, Matsuhiro K, Matsushima T, Mori H, Ohkura T, Yoshikawa S, Miyajima R, Inoue H, Mishima T, Sonoda T, Uchida K, Yamamoto K, Nakamichi H (2016) Preparatory process preceding the 2014 eruption of Mount Ontake volcano, Japan: insights from precise leveling measurements. Earth Planets Space 68:9. https://doi.org/ 10.1186/s40623-016-0386-4

Nakamichi H, Kumagai H, Nakano M, Okubo M, Kimata F, Ito Y, Obara K (2009) Source mechanism of a very-long-period event at Mt Ontake, central Japan: Response of a hydrothermal system to magma intrusion beneath the summit. J Volcanol Geotherm Res 187:167-177. https://doi.org/10. 1016/j.jvolgeores.2009.09.006

Narita S, Murakami M (2018) Shallow hydrothermal reservoir inferred from post-eruptive deflation at Ontake Volcano as revealed by PALSAR-2 InSAR. Earth Planets Space 70:191. https://doi.org/10.1186/s40623-018-0966-6

Ohba T, Yaguchi M, Nishino K, Numanami N, Daita Y, Sukigara C, Ito M, Tsnogai U (2019) Time variations in the chemical and isotopic composition of fumarolic gases at Hakone volcano, Honshu Island, Japan, over the earthquake swarm and eruption in 2015, interpreted by magma sealing model. Earth Planets Space 71:48. https://doi.org/10.1186/s40623-019-1027-5

Ozawa T (1968) Chemical analysis of volcanic gases: I. Chemical analysis of volcanic gases containing water vapor, hydrogen chloride, sulfur dioxide, hydrogen sulfide, carbon dioxide, etc. Geochemistry Int 5:939-947

Rouwet D, Hidalgo S, Joseph EP, González-Ilama G (2017) Fluid geochemistry and volcanic unrest: dissolving the Haze in time and space. In: Gottsmann J, Neuberg J, Scheu B (eds) Volcanic Unrest. Advances in Volcanology. Springer, Cham. https://doi.org/10.1007/11157_2017_12

Seki K, Kanda W, Mannen K, Takakura S, Koyama T, Noguchi R, Yukutake Y, Ishikawa M, Fukai M, Harada M, Abe Y (2020) Imaging the source region of the 2015 phreatic eruption at Owakudani, Hakone Volcano, Japan, using high-density audio-frequency magnetotellurics. Geophys Res Lett. https://doi.org/10.1029/2020GL091568

Sibson RH, Moore JMM, Rankin AH (1975) Seismic pumping - a hydrothermal fluid transport mechanism. J Geol Soc London 131:653-659. https://doi. org/10.1144/gsjgs.131.6.0653

Stix J, De Moor MJ (2018) Understanding and forecasting phreatic eruptions driven by magmatic degassing. Earth, Planets Sp. https://doi.org/10.1186/ s40623-018-0855-z
Symonds RB, Gerlach TM, Reed MH (2001) Magmatic gas scrubbing: Implications for volcano monitoring. J Volcanol Geotherm Res 108:303-341. https://doi.org/10.1016/S0377-0273(00)00292-4

Takagi A, Onizawa S (2016) Shallow pressure sources associated with the 2007 and 2014 phreatic eruptions of Mt. Ontake, Japan. Earth Planets Space 68:135. doi: https://doi.org/10.1186/s40623-016-0515-0

Tanada T, Honda R, Harada M, Yukutake Y, Ito H (2007) Earthquake activity in Kanagawa Prefecture and its adjacent area in 2006. Catfish Lett Hot Springs Res Inst Kanagawa Prefect 57:1-12

Yoshimura R, Ogawa Y, Yukutake Y, Kanda W, Komori S, Hase H, Goto T, Honda R, Harada M, Yamazaki T, Kamo M, Kawasaki S, Higa T, Suzuki T, Yasuda Y, Tani M, Usui Y (2018) Resistivity characterisation of Hakone volcano, Central Japan, by three-dimensional magnetotelluric inversion. Earth Planets Space 70:66. https://doi.org/10.1186/s40623-018-0848-y

Yukutake Y, Abe Y, Doke R (2019) Deep Low-Frequency Earthquakes Beneath the Hakone Volcano, Central Japan, and their Relation to Volcanic Activity. Geophys Res Lett. https://doi.org/10.1029/2019GL084357

Yukutake Y, Honda R, Harada M, Arai R, Matsubara M (2015) A magma-hydrothermal system beneath Hakone volcano, central Japan, revealed by highly resolved velocity structures. J Geophys Res Solid Earth 120:3293-3308

Yukutake Y, Honda R, Harada M, Doke R, Saito T, Ueno T, Sakai S, Morita Y (2017) Continuous volcanic tremor during the 2015 phreatic eruption in Hakone volcano. Earth Planets Space. https://doi.org/10.1186/s40623-017-0751-y

Yukutake Y, Ito H, Honda R, Harada M, Tanada T, Yoshida A (2011) Fluid-induced swarm earthquake sequence revealed by precisely determined hypocenters and focal mechanisms in the 2009 activity at Hakone volcano, Japan. J Geophys Res Solid Earth 116:1-13. https://doi.org/10.1029/2010JB008036

Yukutake Y, Tanada T, Honda R, Masatake H, Ito H, Yoshida A (2010) Fine fracture structures in the geothermal region of Hakone volcano, revealed by well-resolved earthquake hypocenters and focal mechanisms. Tectonophysics 489:104-118

\section{Publisher's Note}

Springer Nature remains neutral with regard to jurisdictional claims in published maps and institutional affiliations.

\section{Submit your manuscript to a SpringerOpen ${ }^{\odot}$ journal and benefit from:}

- Convenient online submission

- Rigorous peer review

- Open access: articles freely available online

- High visibility within the field

Retaining the copyright to your article

Submit your next manuscript at $\boldsymbol{\nabla}$ springeropen.com 